\title{
Effects of Sublevel Open Stope Underground Mining on Surface and Open Pit Slopes
}

\author{
Tumelo K. M. Dintwe1 ${ }^{*}$, Takashi Sasaoka1, Hideki Shimada1, Akihiro Hamanaka', Dyson Moses ${ }^{1}$, \\ Sifei Liu ${ }^{2}$, Fanfei Meng1
}

${ }^{1}$ Department of Earth Resources Engineering, Kyushu University, Fukuoka, Japan

${ }^{2}$ China University of Science and Technology, Xuzhou, China

Email: *dintwe18r@mine.kyushu-u.ac.jp

How to cite this paper: Dintwe, T. K. M., Sasaoka, T., Shimada, H., Hamanaka, A., Moses, D., Liu, S. F., \& Meng, F. F. (2021). Effects of Sublevel Open Stope Underground Mining on Surface and Open Pit Slopes. Journal of Geoscience and Environment Protection, 9, 121-131. https://doi.org/10.4236/gep.2021.91010

Received: December 28, 2020

Accepted: January 26, 2021

Published: January 29, 2021

Copyright $\odot 2021$ by author(s) and Scientific Research Publishing Inc. This work is licensed under the Creative Commons Attribution International License (CC BY 4.0).

http://creativecommons.org/licenses/by/4.0/

\begin{abstract}
Underground mining is an economically viable option for exploiting ore reserves deemed uneconomic after open pit mining. However, underground development can have adverse effects on the above existing open pit slope walls. As a goal of this paper, identification and assessment of potential slope instabilities prior to underground development is crucial for safe and sustainable mining. Towards goal achieving, this paper gives a comprehensive parametric study to investigate the influence of sublevel open stope (SLOS) underground mining on the surface and open pit slope walls. By means of numerical simulation, the SLOS design is tried against the existing open pit followed by adjustments of important slope parameters which are overall slope height (OSH) and overall slope angle (OSA). We found that underground mining may induce slope failure, particularly on the hangingwall side of the pit. Subsidence is prominent on the hanging wall and the surface, whereas, the uplift dominates the footwall and pit bottom. Pit wall closure is observed during underground mining. Although the assigned dimensions in the parametric study show a negligible effect of OSH and OSA, the high OSH experience low subsidence in comparison with low OSH. Overall, the results demonstrate that the slope walls on the hanging wall side are mostly affected by the underground mining and high-stress concentration prevails near slope toes and pit bottom. Additionally, slope deformation decrease from pit bottom towards the slope crest and surface. The results of this study add knowledge to open pit and underground mining interaction.
\end{abstract}

\section{Keywords}

Open Pit-Underground Interaction, Slope Stability, Underground Mining, Subsidence 


\section{Introduction}

The lifetime of a mine may be extended by transitioning from open pit (OP) mining to underground (UG) mining. Reason for the transformation being that surface mining is non-profitable when the pit reaches certain depth. Taking into consideration the quantity of the waste associated with open deep pits and the resulting steepened high walls, underground mining is then more attractive to exploit ore reserves. Moreover, the steepened high slope walls generally threaten the structural integrity of the pit and lead to instabilities. While considering the viable underground mining, presence of the open pit structure over the underground mine presents not just new but rather complex challenges ranging from surface subsidence, slope deformation, mud rushes, and crown pillar collapse to underground instabilities. Slope management of an open pit is a challenging deed on its own, particularly for large open pits, which usually requires dedicated team for continuous monitoring, necessary for hazard prediction and identification. With the integration of underground mine below, it is most likely that the geotechnical challenges associated with the slope be worsened.

Hamman et al. (2020) classify transition scenarios into three namely 1. Open pit transitioning to underground, where there will be simultaneous operation of $\mathrm{OP}$ and UG for some period before OP closes 2. Underground mining below existing open pit, where UG only commences after OP closure, lastly 3. Open pit mining on abandoned underground mines. Though, surface mining ceases upon introduction of underground mining in scenario 2, in which this study focuses on, the OP section will still require utmost monitoring and management. Slope failures are time-dependent, meaning it is possible for slope movement to take place gradually over a long period of time and only to fail after surface mining has stopped. Underground mining is among the most likely causes for slope failures post surface mining. Moreover, in many cases, near the pit bottom or somewhere along the slope will serve as entry to the UG section by adits or declines, therefore safe slopes ought to be guaranteed.

The underground mining may cause surface settlement triggering slope failures that may even extend beyond local zones to the neighbouring areas and damage surface infrastructures. Open pit slope failure has a significant impact on success and life of the mine too. Depending on the scale of failure, it might force mine closure and render mining unsustainable as was the case in Thabazimbi mine, South Africa. In the case of ore loss due to slope failure caused by underground mining below the pit, Palabora mine anticipated loss tantamount to $30 \%$ of the ore reserve (Ngidi \& Boshoff, 2007). Ernest Henry mine, Australia, suffered from high slope deformations as the wall collapsed due to sublevel caving below open pit mine (Campbell \& Lilley, 2018). It was highlighted that the cave propagation to the slope walls in both Ernest Henry and Pilabora mines was controlled by the persistent geological structures (faults). The failures were simulated and structural control on the failure was captured by these simulations, proving the importance of numerical methods in OP-UG interaction. 
For tabular steep ore bodies, the OP and UG sections are contiguous to each other and only separated by a crown pillar. The pillar provides a buffer zone, often not enough to provide global stability. Such ore bodies are suitable for underground mining methods such as cut and fill or open stopping methods, and in addition to the crown pillar, sill pillars and backfill may be adopted to ensure stability. During the underground mining, the walls of the slope are basically drawn towards the center (pit bottom) signifying wall closure (Ding-Bang et al., 2014; Zhou et al., 2016). The closure may be accompanied by vertical movement either by subsidence or uplift along the open pit structure (Zhao et al., 2013). The slope instabilities are, therefore expected, but how and to what extent will they occur is of interest in geomechanics. The control is not just limited to the geological structures, but also the geometry of the pit could as well influence the slope failure in response to underground mining. Additionally, the type of underground mining method adopted has a significant influence on the surface and slope deformations. The surface response, for instance, due to block caving is relatively different from cut and fill mining coupled with site specifications.

This paper investigates the potential influence of SLOS underground mining on the above surface and open pit slope deformations. Focus is on the open pit geometry and its effects on the OP-UG interaction. For logical and clear understanding of OP-UG interaction, an integrated numerical model consisting of an existing open pit section and active underground mine was constructed to represent the Zuuntsagaan Del mine, Mongolia. The numerical model simulation intends to decipher various possible scenarios relating to open pit geometry, thus, overall slope angle (OSA), and overall slope height (OSH) effects in response to underground mining.

\section{Geology and Geotechnical Description}

The geology of the study area consists of andesite and basaltic rocks, with an orebody characterized by massive quartz fluorite veins and carbonates. Based on the strength of rock and rock mass, the rock mass is regarded to be competent. The orebody is tabular and steeply dipping at average of $70^{\circ}$ in the north east direction, along the strike line of $25^{\circ}$. Average thickness of the ore body is $10 \mathrm{~m}$ varying from 0.5 to $20 \mathrm{~m}$ along the $200 \mathrm{~m}$ strike length. The ore extends from the pit bottom into the subsurface at measured depth of 195 .

The mine rock mass exhibit highly jointed surfaces with at least three discontinuity sets, and the discontinuity surfaces have low alteration and mostly rough. The mine rock mass has been subjected to the extreme temperatures of winter that leads to freezing and thawing of rocks. The cyclic process of freezing and thawing reduces the rock mass strength. Nevertheless, rock mass rating carried by out at the mine utilizing various rock mass classification systems described the rock mass in Zuuntsagaan mine as Good (67) on Rock mass rating (RMR) scale (Bieniawski, 1973) and rated on (Hoek \& Brown, 1997) Geological strength index (GSI) at 62.5 . 
In the period of 29 years, 1978 to 2007, the Zuuntsagaan mine was operating through open pit mining and ceased operation due to economic reasons. Currently, the mine is undergoing plans of underground mining by SLOS. The rock mass is competent hence the selection of the SLOS method. The vein is relatively narrow, therefore, it will be explicitly targeted through the longitudinal configuration. An overhand approach is adopted due to the stress management in the bottom up approach (Potvin \& Hudyma, 2000). The stope dimensions are 10m height by $20 \mathrm{~m}$ long. The sequence is such that after 2 excavations of each level, sill pillars are left to provide support and working floor. This is then followed by backfilling and recovery of secondary stopes. However, for this study the whole region was excavated sequentially without backfill and monitored to realise full possible deformation of the surface.

\section{Numerical Analysis}

\section{Model Construction}

The model was built using FLAC 3D, in which the open pit section that was previously mined out and the active underground mine are set up. Each section is presented in Figure 1 showing the ore body located in the underground section adjoining the hangingwall and footwall. The model stretches to $1200 \mathrm{~m}$ along the long axis and $600 \mathrm{~m}$ on the short axis. The slope parameters (berm and bench height which translates to OSH and OSA) are designed with fish script to permit adjustments specified by the user. The model bottom is restricted in all directions by pinned boundary and on the horizontal limits, roller boundaries are assigned to allow only vertical movement. The top boundary is free, letting the dead weight to act under gravity. Figure 2 presents all the monitoring points, positioned at
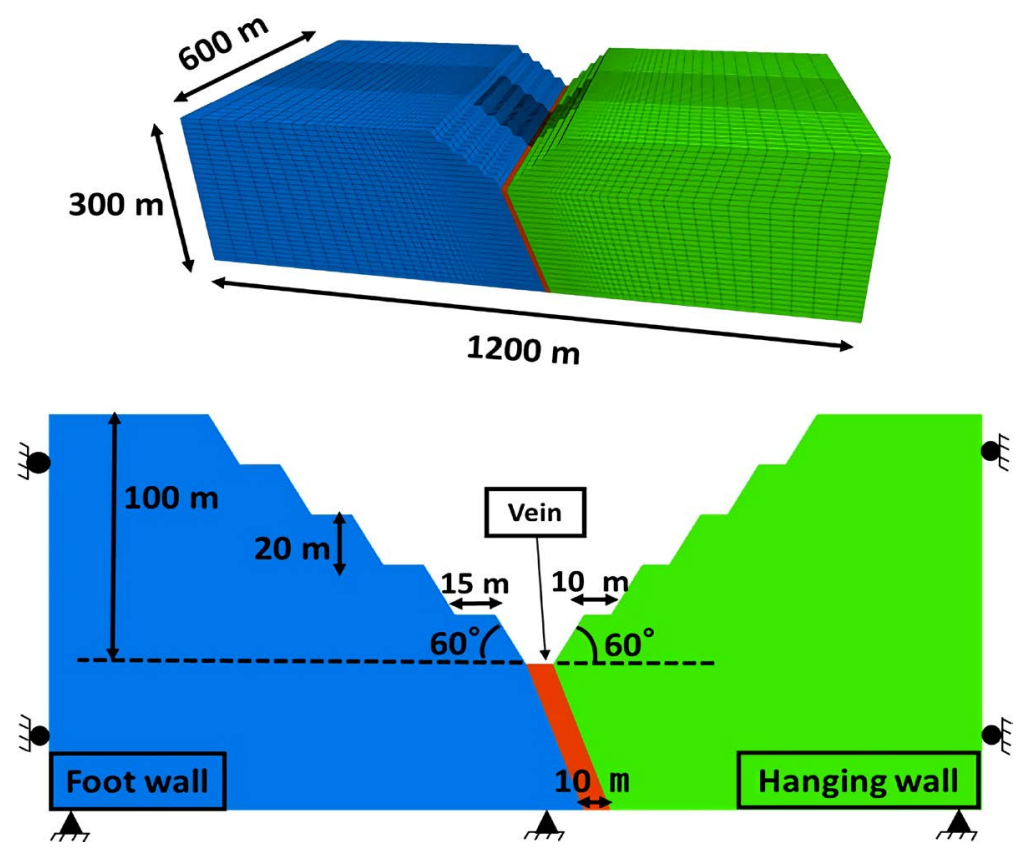

Figure 1. Model set up showing dimensions. 


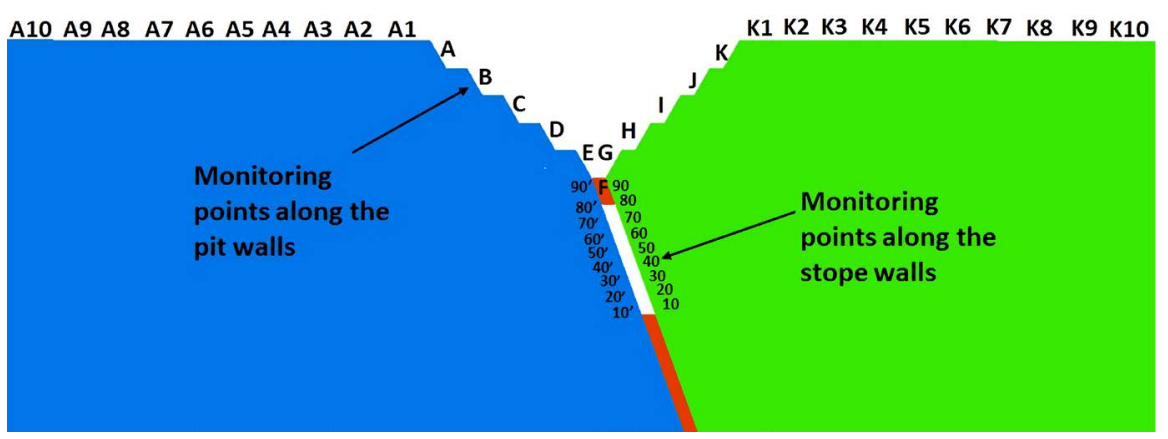

Figure 2. Monitoring points along the mid-section of the model.

the center of the model along the short axis. The points cover the open pit slopes and $500 \mathrm{~m}$ surface beyond the slope crest.

Due to lack of in situ stress measurements, to estimate the in situ stresses prevailing at the mine site, focal mechanism was applied to estimate the principal stresses. With available geological features such as faults striations and folds together with focal mechanism solution (Aydan, 2000, 2016) suggests that the crustal stresses may be estimated. The model is governed by Mohr Coulomb criterion following the elasto-plastic path of material strength. With Aydan's method it is established that the largest principal stress act almost perpendicular to the short axis of the open pit. Physio-mechanical parameters used for the model are obtained from laboratory tests, followed by rock mass characterization using rock mass classification see Table 1 .

\section{Results and Discussions}

Various stability indicators are used in rock mechanics and rock engineering. In this study, based on the capabilities of the numerical simulation, displacement, stress and yielding zones were monitored to evaluate stability. This section, therefore focus on the model response results obtained on the surface and slope walls.

\subsection{Surface and Slope Deformations}

Stability of the slope under the actual conditions was monitored during the underground mining, the displacement, stress and yielding zones of the slope section are presented in Figures 3-5 respectively. The maximum horizontal and vertical displacement monitored on the slope is $38 \mathrm{~mm}$ and $22 \mathrm{~mm}$ respectively. For lateral deformation, the hangingwall endures larger deformation than the footwall. Meanwhile, from lateral displacement history, the pit bottom (monitoring point F) appears to be stable with least displacement values. Vertical deformation analysis indicates two significant deformation patterns, 1) Uplift on the footwall side together with the pit bottom 2) Subsidence on hangingwall and part of the surface, and similar deformation pattern has been reported in the Longshou mine, China (Ma et al., 2012; Zhao et al., 2013). In both vertical and horizontal displacements there is a general increase with the mining steps, thus 
Table 1. Physio-mechanical rock properties.

\begin{tabular}{cccccc}
\hline Material & $\begin{array}{c}\text { Elastic modulus } \\
(\mathrm{GPa})\end{array}$ & Poisson ratio & $\begin{array}{c}\text { Cohesion } \\
(\mathrm{MPa})\end{array}$ & Friction Angle $\left(^{\circ}\right)$ & $\begin{array}{c}\text { Tensile } \\
\text { strength }(\mathrm{MPa})\end{array}$ \\
\hline Host rock & 13.3 & 0.25 & 1.63 & 45 & 0.28 \\
Vein & 12.3 & 0.27 & 1.32 & 42 & 0.24 \\
\hline
\end{tabular}

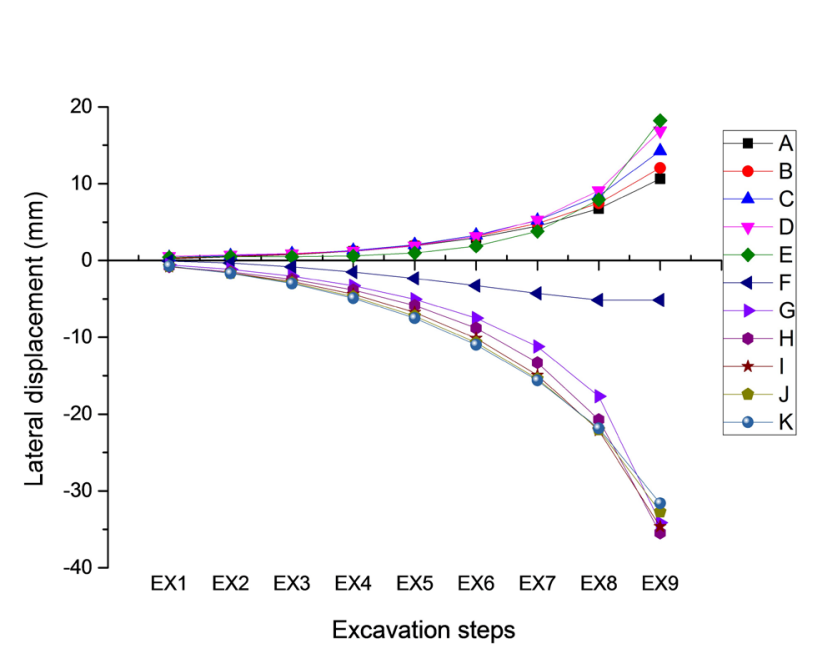

(a)

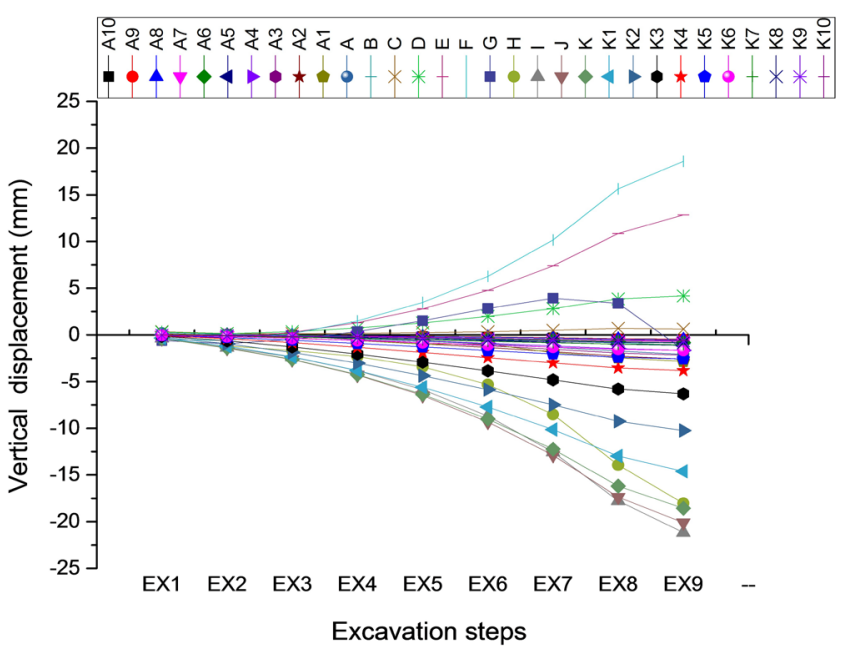

(b)

Figure 3. Displacement distribution (a) Lateral displacement; (b) Vertical displacement.

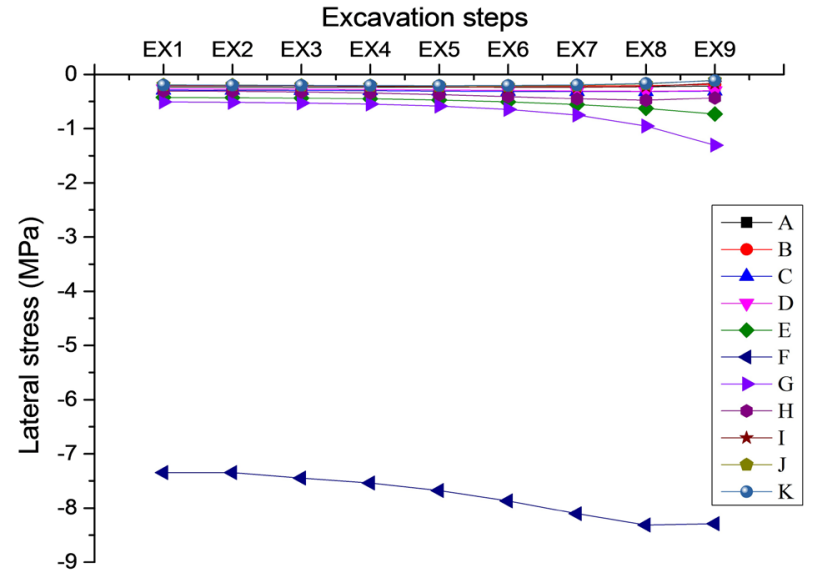

(a)

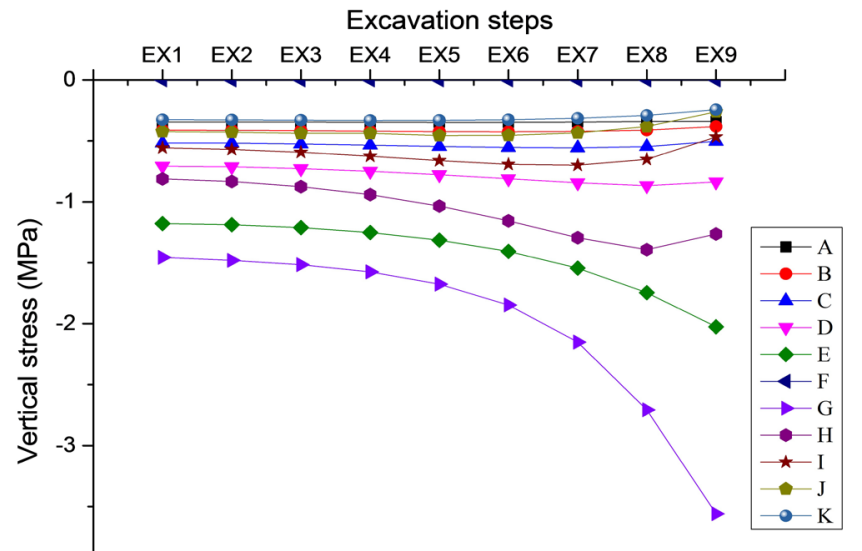

(b)

Figure 4. Stress distribution (a) Lateral displacement; (b) Vertical displacement.

approaching the pit bottom. However, history shows the pit bottom is most affected by vertical deformation the maximum is recorded here, see Figure 3(b), and horizontal movement will be constrained as indicated in Figure 3(a).

Figure 4 presents the stress variation plots of the open pit section and the stress redistribution is in good agreement with the displacement pattern. Figure 4(b) shows higher stresses on the hangingwall than on the footwall, hence the displacement patterns observed. However, at the pit bottom, the two lateral stresses from the slope walls act as confining stresses restricting the lateral movement in 

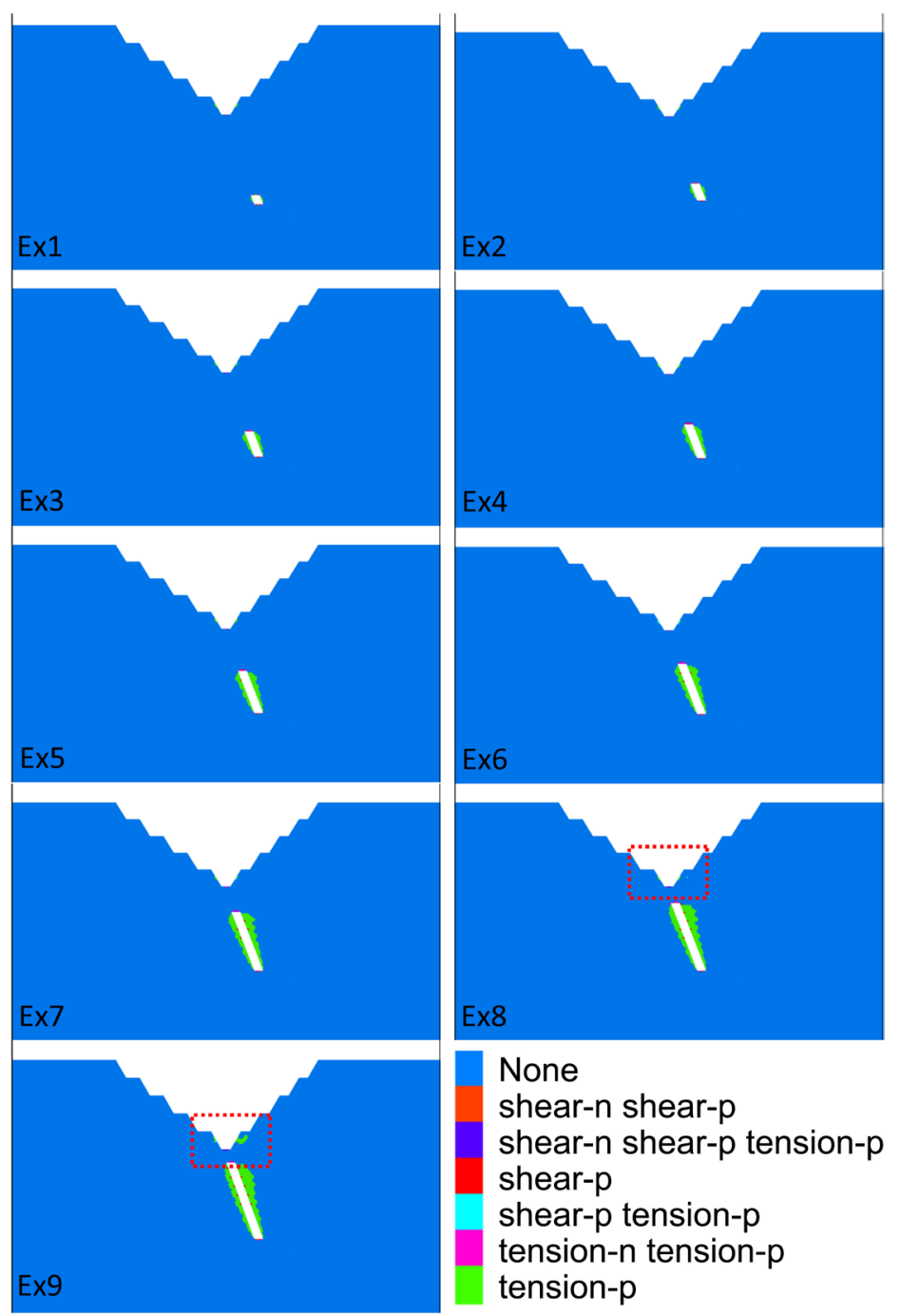

Figure 5. Yielding zones showing the affected area due to underground mining.

the process, see Figure 4(a) of the adjacent footwall and hangingwall. The resultant stresses due to two rock mass bodies moving towards each other, forces rock mass uplift on the pit bottom and footwall, and subsidence of the hangingwall. As with the displacement, the stresses tend to rise with each mining step, this is clearly highlighted on the vertical stress distribution. Experimental work by Zhou et al. (2016) indicated that the stress concentration in open pit transition mine is likely to occur around the slope toes and in this study the stress variation around the pit indicates that it increases towards the slope toes as mining progresses.

Yielding zones offers qualitative damage assessment of the rock mass damage. This is made possible by zone identification of parts affected or damaged by the stress redistribution resulting from underground mining. Rock mass may fail under different forms of failure including tension, shear or combined failure. Indeed, near the slope toe area and pit bottom are more impacted by the underground mining as shown in Figure 5. Failure around the slope gradually grows 
as underground mining progresses upwards. Also, it is observed the slope toe on the hanging wall is mostly affected, failure starts on the surface of the slope and propagates behind the bench of the slope. Combined failure is observed on the surface of pit bottom (crown pillar) and tensional failure on the surface slope toe of the footwall. However, almost half of the bench on the slope toe in hanging wall indicates to be compromised.

\subsection{Effects of Overall Slope Angle (OSA)}

A few degrees change in slope angle is enough to cause massive slope failure or stabilize it. The latter is achievable by push back. Every open pit mine has an OSA set at the design stage looking at the site conditions such as rock mass characteristics (lithology, topography, ore morphology etc.). The mine may be stable during the open pit mining until end of its mine life. The set OSA could be

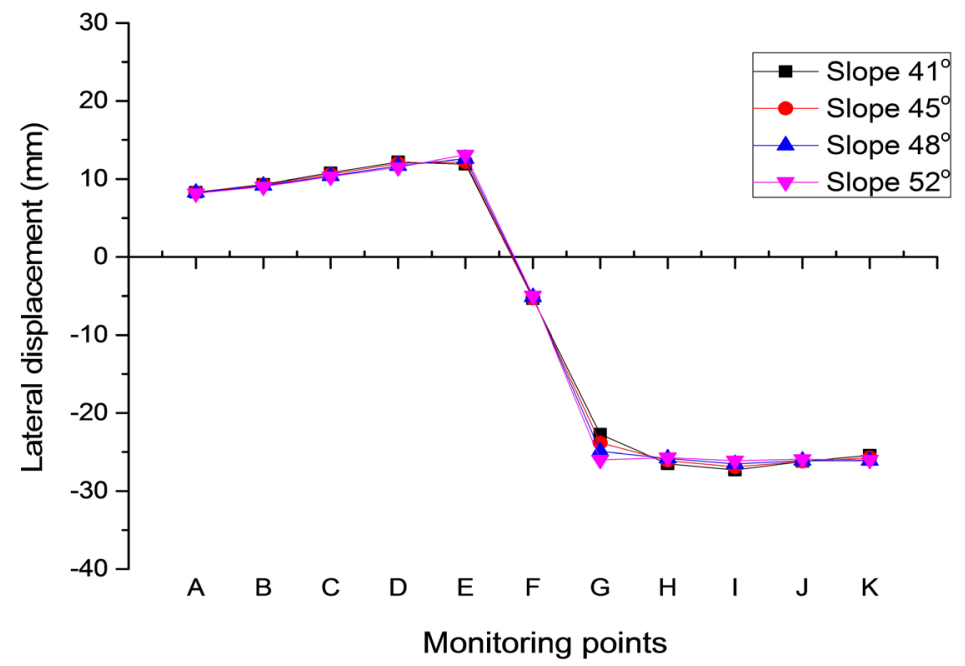

(a)

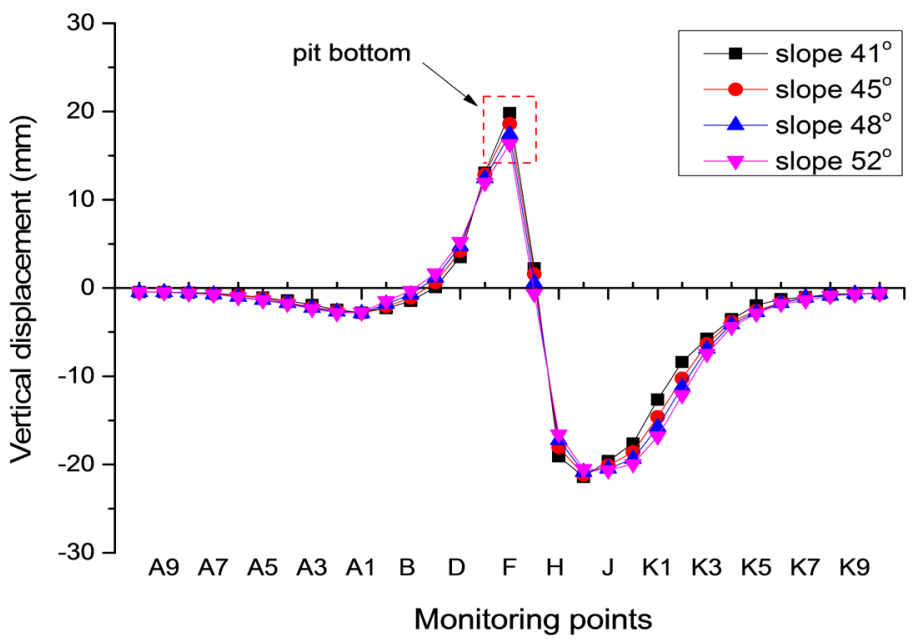

(b)

Figure 6. Displacement distribution of varied OSA (a) Lateral displacement; (b) Vertical displacement. 
only good for the surface mining and not necessarily favourable for underground mining. At the transition stage, the designers have permanent OSA to contend with while planning for the underground. This is because the OSA influence the stability of the slope wall, and underground activities may trigger slope deformation that lead to slope and surface failures.

This study seeks to understand the influence of OSA on the slope walls in response to underground mining. Four cases of OSA were investigated $\left(41^{\circ}, 45^{\circ}\right.$, $48^{\circ}$, and $52^{\circ}$ ) as shown in Figure 6 and it is observed that there is no significant difference in the lateral displacement, but it the steep OSA tend to have large displacement towards the pit bottom, see Figure 6(a). The estimated maximum uplift displacements at the pit bottom for $\left(41^{\circ}, 45^{\circ}, 48^{\circ}\right.$, and $\left.52^{\circ}\right)$ are $21,19,17$ and $15 \mathrm{~mm}$ respectively as shown. The trend is such that when the slope angle increases the uplift decrease, hence $52^{\circ}$ OSA records the lowest uplift displacement. Regarding the subsidence on the hangingwall it is noted that there is no significant difference in the displacement. Nonetheless, upon close scrutiny of the plot, subsidence is maximum for the gentle slope $\left(41^{\circ}\right)$ at $23 \mathrm{~mm}$ displacement.

\subsection{Effects of Overall Slope Height (OSH)}

As the open pit mining progresses down wards, the pit diameter or lateral axis increases during the subsequent cuts together with OSH. High slopes are known to be prone to complex slope failures due to the volume of the exposed rock mass. Large geological structures often have control over large domains and the continuity may extend such that the overall slope failure could occur. The common bench heights in most mines vary for $10-18 \mathrm{~m}$ (Loig et al., 2010). For this parametric study $12,14,16,18$ and $20 \mathrm{~m}$ bench heights are investigated translating to the OSH of 60, 70, 80, 90 and $100 \mathrm{~m}$ respectively. Figure 7 illustrates the simulated displacements at varied heights. Lateral movement is lower in the footwall than in the hangingwall, however, the displacement of the highest OSH $(100 \mathrm{~m})$ appears to rise towards the slope toe whereas other cases show a decrease. It can be seen from

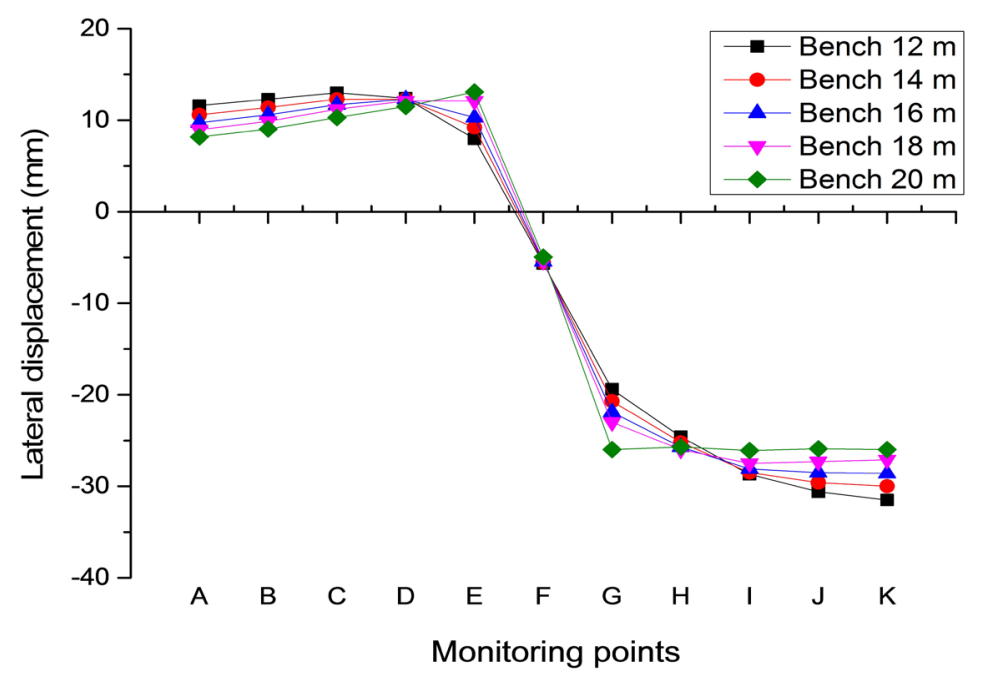

(a) 


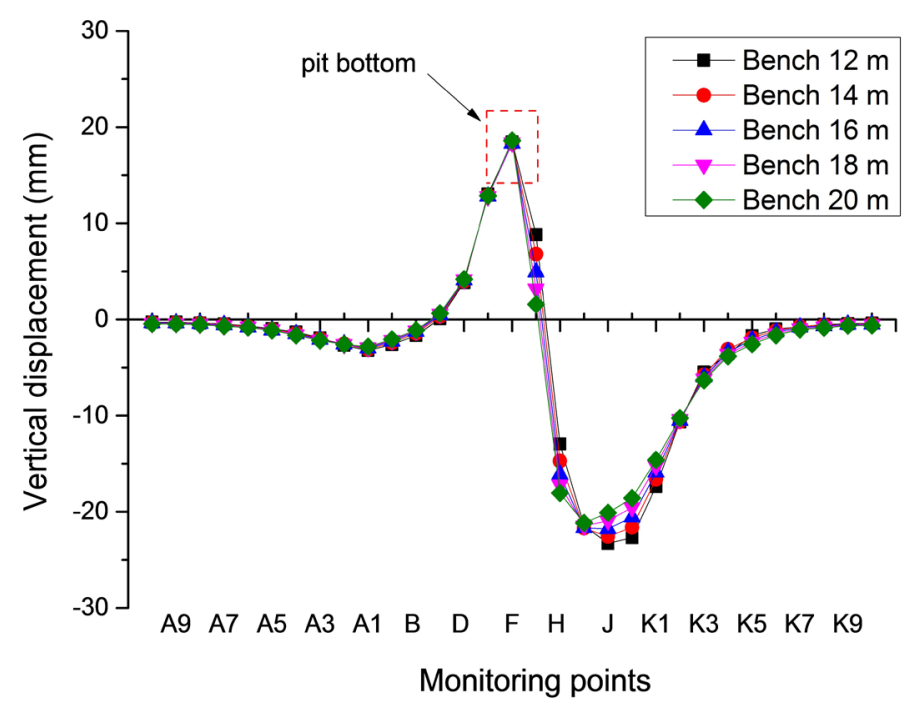

(b)

Figure 7. Displacement distribution of varied OSH (a) Lateral displacement; (b) Vertical displacement.

Figure 7(b) that the uplift and subsidence displacements values are almost the same. However, $60 \mathrm{~m}$ OSH shows slightly higher values of subsidence and the subsidence reduces as the OSH increases.

\section{Conclusion}

A study was conducted to investigate the effects of mining below an existing open pit by SLOS. Thus, it aimed to understand slope deformation patterns and the influence of critical mine aspects; OSH and OSA. In carrying out the investigation a 3D numerical model was established to represent the two sections (underground and open pit) of the mine. This study has shown that the underground mining may have adverse effects on open pit slopes triggering slope deformations. It was observed that slopes above the hangingwall are mostly affected by the underground mining than the walls of the slope above the footwall. Stresses along the slope wall are concentrated on the slope toes and pit bottom. Uplift and subsidence of the pit wall are observed as a result of the underground mining. The parametric study of OSA and OSH has been shown to be affected by the underground mining and more especially at lower values. A full study where both underground and open pit sections are analysed is required to further understand the influence of underground mining on the overall stability of the mine.

\section{Acknowledgements}

The authors would like to thank the Japan MEXT program for the financial assistance in carrying out this study.

\section{Conflicts of Interest}

The authors declare no conflicts of interest regarding the publication of this paper. 


\section{References}

Aydan, Ö. (2000). An Stress Inference Method Based on Structural Geological Features for the Full-Stress Components in the Earth' Crust. Yerbilimberi, 22, 223-236

Aydan, Ö. (2016). An Integrated Approach for the Evaluation of Measurements and Inferences of In-Situ Stresses. In ISRM International Symposium on In-Situ Rock Stress, 10-12 May 2016. Finland: Tampere.

Bieniawski, Z. T. (1973). Engineering Classification of Jointed Rock Masses.

Campbell, A., \& Lilley, C. (2018). Cave Propagation and Open Pit Interaction at the Ernest Henry Mine Cave Propagation and Open Pit Interaction at the Ernest Henry Mine. In Seventh International Conference and Exhibition on Mass Mining (pp 1-16). Sydney.

Ding-Bang, Z., Chuan-Bo, Z., Yang-Bo, L., \& Jian-Yi, Y. (2014). Physical Model Test and Numerical Simulation Study of Deformation Mechanism of Wall Rock on Open Pit to Underground Mining. International Journal of Engineering, Transactions B: Applications, 27, 1795-1802.

Hamman, E., Cowan, M., Venter, J., \& de Souza, J. (2020). Considerations for Open Pit to Underground Transition Interaction. Slope Stability 2020, 1123-1138. https://doi.org/10.36487/ACG_repo/2025_74

Hoek, E., \& Brown, E. T. (1997). Practical Estimates of Rock Mass Strength. International Journal of Rock Mechanics and Mining Sciences, 34, 1165-1196.

Loig, L., Stacey, P., \& Read, J. (2010). Slope Design Methods. In Read, J., Stacey, P., (eds.), Guidelines for Open Pit Slope Design (p 485). CRIRO.

Ma, F., Zhao, H., Zhang, Y. et al. (2012). GPS Monitoring and Analysis of Ground Movement and Deformation Induced by Transition from Open-Pit to Underground Mining. Journal of Rock Mechanics and Geotechnical Engineering, 4, 82-87. https://doi.org/10.3724/SP.J.1235.2012.00082

Ngidi, S., \& Boshoff, P. (2007). Cave Management and Secondary Breaking Practices at Palabora Mining Company. Journal of the Southern African Institute of Mining and Metallurgy, 107, 782-789.

Potvin, Y., \& Hudyma, M. (2000) Open Stope Mining in Canada. In Massmin 2000 (661-674). Brisbane.

Zhao, H., Ma, F., \& Zhang, Y. (2013). Monitoring and Analysis of the Mining-Induced Ground Movement in the Longshou Mine, China. Rock Mechanics and Rock Engineering, 46, 207-211. https://doi.org/10.1007/s00603-012-0232-3

Zhou, C., Lu, S., Jiang, N. et al. (2016). Rock Mass Deformation Characteristics in High-Steep Slopes Influenced by Open-Pit to Underground Mining. Geotechnical and Geological Engineering, 34, 847-866. https://doi.org/10.1007/s10706-016-0009-7 